\title{
A Preliminary Checklist of Fungi at the Boston Harbor Islands
}

\author{
Danny Haelewaters ${ }^{1, *}$, Alden C. Dirks ${ }^{1,2}$, Lara A. Kappler ${ }^{1,3}$, James K. Mitchell ${ }^{1,4}$, \\ Luis Quijada ${ }^{1,5}$, Roo Vandegrift ${ }^{6}$, Bart Buyck ${ }^{7}$, and Donald H. Pfister ${ }^{1}$
}

\begin{abstract}
Between December 2012 and May 2017, we conducted a fungal inventory at the Boston Harbor Islands National Recreation Area (BHI) in Massachusetts. We extensively sampled 4 sites (Grape Island, Peddocks Island, Thompson Island, and World's End peninsula) and occasionally visited 4 others for sampling (Calf Island, Great Brewster Island, Slate Island, and Webb Memorial State Park). We made over 900 collections, of which 313 have been identified. The survey yielded 172 species in 123 genera, 62 families, 24 orders, 11 classes, and 2 phyla. We report 4 species as new, but not formally described, in the genera Orbilia, Resupinatus, and Xylaria. Another collection in the genus Lactarius may be new to science, but further morphological and molecular work is needed to confirm this conclusion. Additionally, Orbilia aprilis is a new report for North America, Proliferodiscus earoleucus represents only the second report for the US, and Chrysosporium sulfureum, a common fungus of some cheeses, was discovered on woodlice (Crustacea: Malacostraca: Isopoda: Oniscidea). We discuss our findings in the light of DNA-based identifications using the ITS ribosomal DNA region, including the advantages and disadvantages of this approach, and stress the need for biodiversity studies in urbanized areas during all seasons.
\end{abstract}

\section{Introduction}

The Boston Harbor Islands National Recreation Area (BHI), the only drumlin archipelago in the US (Himmelstoss et al. 2006), comprises 34 islands and peninsulas scattered between the protection of Boston's inner harbor and its vulnerable outskirts. The outer islands are dominated by bare rock, blasted by sea spray, wind, and waves. The inner-island habitats are varied, and are characterized by sandy coastlines, bluffs, and rocky intertidal areas transitioning into densely vegetated interiors, tidal estuaries, and meadows. Most notably, over hundreds of years, the Boston Harbor Islands have been subjected to human disturbances such as agricultural clear-cutting and grazing; construction of military fortifications, hospitals,

\footnotetext{
${ }^{1}$ Farlow Herbarium of Cryptogamic Botany, Harvard University, 22 Divinity Avenue, Cambridge, MA 02138. ${ }^{2}$ Current address - Great Lakes Bioenergy Research Center, University of Wisconsin-Madison, 1552 University Avenue, Madison, WI 53726. ${ }^{3}$ School for the Environment, University of Massachusetts-Boston, 100 William T. Morrissey Boulevard, Boston, MA 02125. 'Department of Physics, Harvard University, 17 Oxford Street, Cambridge, MA 02138. ${ }^{5}$ Department of Botany, Ecology, and Plant Physiology, University of La Laguna, 38200 La Laguna, Tenerife, Canary Islands, Spain. ${ }^{6}$ Institute of Ecology and Evolution. 335 Pacific Hall, 5289 University of Oregon, Eugene, OR 97403-5289. ${ }^{7}$ Muséum National d'Histoire Naturelle, Département Systématique et Évolution, CP 39, ISYEB, UMR 7205 CNRS MNHN UPMC EPHE, 12 Rue Buffon, F-75005 Paris, France. *Corresponding author - dhaelewaters@fas.harvard.edu.
}

Manuscript Editor: David Richardson 
and other institutions; introduction of terrestrial and marine exotic species; and fire exposure (Snow 1984).

Protecting biodiversity and natural habitats from anthropogenic stressors is a primary objective of managers of public parklands. The first step in managing areas to avoid the loss of imperiled species is understanding the diversity and ecology of species; only then can managers consider protective actions and understand which stressors may be of larger concern. An All-Taxa Biodiversity Inventory (ATBI) is a way to discover and identify all living organisms in a particular area over a specified time frame of intense study (Janzen and Hallwachs 1994). In 1998, the National Park Service established an inventory and monitoring program in order to document the biodiversity of parks with significant natural resources and track the vital signs of park ecosystems (Fancy et al. 2009). The program, however, focuses on vertebrate animals and vascular plants. Thus, a full understanding of park biodiversity requires additional studies.

One such study was conducted from 2001 to 2002 on the bryophyte and lichen floras of BHI-2 often-overlooked groups. A total of 107 person-days of collecting across 33 field-sites resulted in the documentation of 175 species of lichens and 70 species of bryophytes (LaGreca et al. 2005). Samples from each species are vouchered at the Farlow Herbarium, Harvard University. Certain lichens and bryophytes representative of common maritime communities were not present likely due to a legacy of air pollution from the Boston metropolitan area and human disturbances such as construction and foot traffic. However, La Greca et al. (2005) noted that air pollution from Boston was diminishing over time and that their collecting efforts would offer a valuable reference for future comparisons as environmental regulation, urban development, and climate change continue to modify the natural communities at the BHI.

Between 2005 and 2010, the Boston Harbor Islands Partnership and the Harvard University Museum of Comparative Zoology (MCZ) collaborated to implement a terrestrial invertebrate ATBI of the BHI. This effort brought together a diverse group of park volunteers, interns, citizen scientists, students, and more than 40 taxonomists from North America and Europe to study what Harvard professor E.O. Wilson calls the park's "microwilderness". The invertebrate inventory resulted in the collection of 83,632 specimens and the identification of 2094 species (B.D. Farrell, Harvard University, Cambridge, MA; pers. comm.). The collected insect specimens are permanently housed at the MCZ. The substantial amount of work that is involved in preserving and curating the collection generated hands-on experience for high school students and undergraduates across the state. The information from the ATBI also aided in the creation of multiple educational tools that are used to engage thousands of middle school students (Lazarus 2013, Rykken 2013, Rykken and Farrell 2013, Zimkus 2015).

In 2013, the National Park Service and Farlow Herbarium at Harvard University began a second phase of research on the park's microwilderness ATBI when D. Haelewaters indicated interest in studying an order of parasitic fungi (Laboulbeniales) that he found in the BHI insect collections at the MCZ. Fungi in Laboulbeniales 
(phylum Ascomycota, class Laboulbeniomycetes) form fruiting bodies on the exoskeleton of invertebrates and thus are relatively easily seen on dried insect collections. This inventory led to 20 records of Laboulbeniales (Haelewaters et al. 2015, unpubl. data) and ultimately resulted in the development of a systematic program to document non-lichenized fungi at the BHI. During this effort, we have worked with volunteers, interns from the University of Massachusetts-Boston, citizen scientists, and researchers to study the fungi at the Boston Harbor Islands.

Fungi have a variety of lifestyles: some are saprobic, breaking down dead organic matter and fulfilling vital roles in nutrient recycling, whereas others form associations with host organisms that can range from mutualistic to parasitic. Fungi are also sensitive to variations in temperature, humidity, and nutrients; their abundance or scarcity in response to environmental changes provides a useful indication of subtle changes within an environment (Nilsson et al. 2009). Studies of biological diversity at the Boston Harbor Islands aim, in part, to reveal patterns that influence the ecological community as a whole and inform resource-protection management decisions (Trowbridge et al. 2011). By establishing a comparative baseline of biodiversity data over time, it is possible to detect early changes, with particular focus on anthropogenic changes, that warrant adaptation and mitigation measures (Begerow et al. 2010).

Accuracy in biodiversity assessments relies on bottom-up consistency, beginning with accurately identified species (Begerow et al. 2010). At present, one of the largest gaps in our taxonomic knowledge lies within Fungi (Bluhm et al. 2011). In part, these gaps can be attributed to the geographical dispersion of historical data sources (Begerow et al. 2010). In recent years, however, the application of molecular techniques has revealed that there is much more to the kingdom of Fungi than meets the eye. The incorporation of DNA-based species delimitation has exposed the restrictions of morphological assessments and casts doubt upon some earlier taxonomic assignments. Fungi are not only ubiquitous but much more diverse than previously recognized; only $1-2 \%$ of the estimated $5-10$ million species of fungi are described (Bass and Richards 2011, Blackwell 2011, Blaxter 2004, Hawksworth and Lücking 2017, Nilsson et al. 2009).

The availability of DNA sequencing technology has prompted the development of collaboratively assembled DNA-sequence databases available to the public and critically reviewed by experts (Begerow et al. 2010, Kõljalg et al. 2013). At a moment of unprecedented global biodiversity loss, and with a vast majority of fungal species being undescribed (Korf 2005, Pimm et al. 2014), it is imperative not only to take advantage of the most up-to-date technologies, but to push forward on collection efforts. As Richard P. Korf (2005:410) wrote: "We must collect, collect, and collect." There is a critical need for funding, specifically for biodiversity collection efforts, as well as increased training for students in collections-based research: we must train our students to leave the laboratory and to go out into the field, from the frozen arctic to the humid tropics. Without documented specimens, no assay of biodiversity has meaning (Korf 2005, Truong et al. 2017). 


\section{Field-site Description}

We targeted 3 islands and 1 peninsula for the BHI fungal ATBI between December 2012 and May 2017: Grape Island, Peddocks Island, Thompson Island, and World's End peninsula. On average, 154 person-hours $(\min =108, \max =224)$ were spent collecting at each of those locations. Calf Island, Great Brewster Island, Slate Island, and Webb Memorial State Park were also occasionally sampled for an average 17.5 person-hours $(\min =12, \max =32)$ per site $($ Fig. 1$)$. These land

Figure 1. Overview of the fungal species richness at the BHI by field-site for our sampled target sites. Islands in grey and black are part of the Boston Harbor Islands National Recreation Area. Those in black are fieldsites referred to in this paper: $\mathrm{CI}=$ Calf Island, GBI $=$ Great Brewster Island, GI = Grape Island, PI = Peddocks Island, $\mathrm{SI}=$ Slate Island, TI = Thompson Island, WE $=$ World's End peninsula, and $\mathrm{WMSP}=$ Webb Memorial State Park. Each target site is circled, and 2 numbers are given for each; the first number is the total number of species found at that site, and

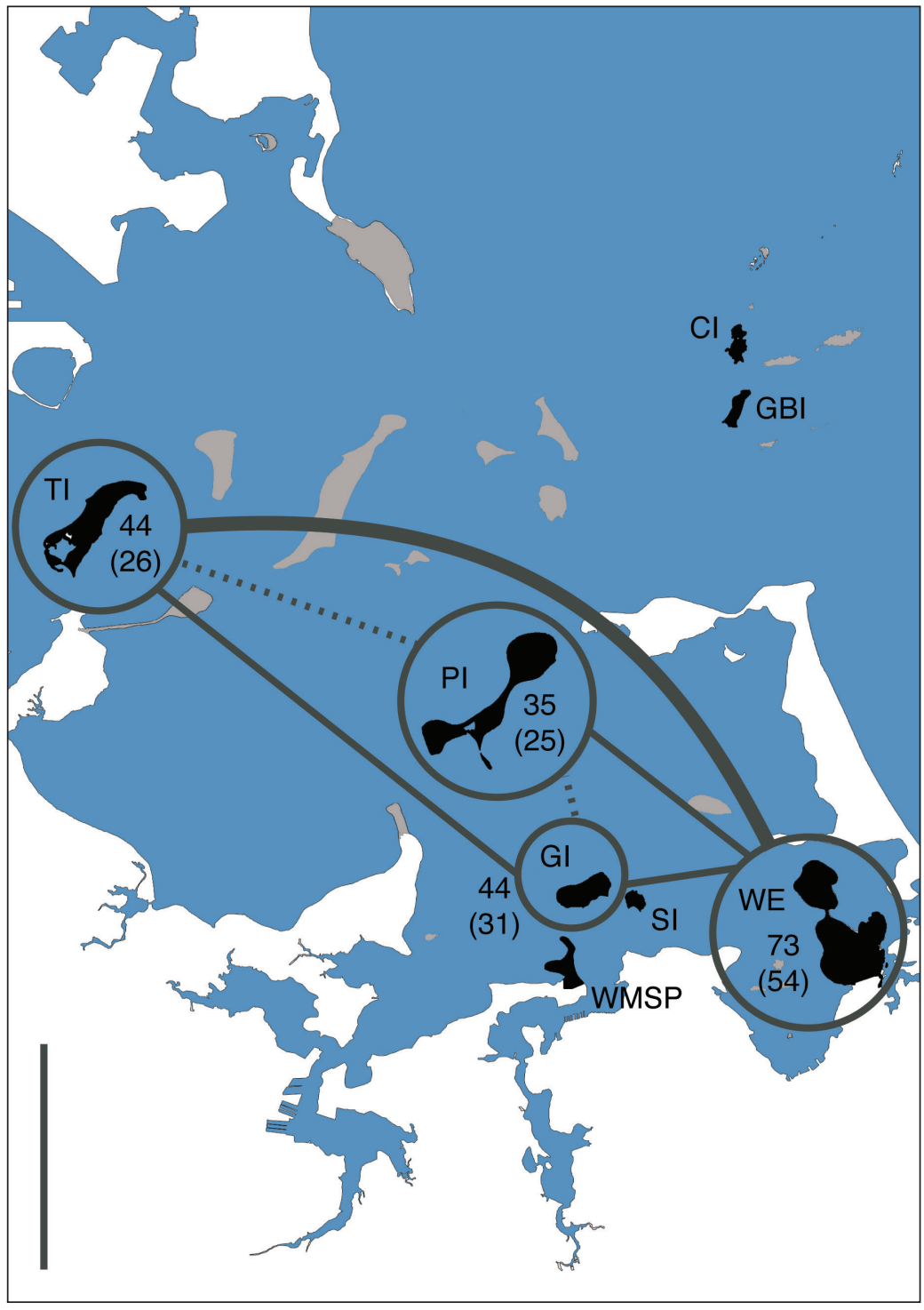
the second (between parentheses) represents the number of exclusive species per target sitethose collected nowhere else at the Boston Harbor Islands. The lines connecting the 4 target sites indicate the number of shared species: thin dotted line $=4-7$ species, thin full line $=8-12$ species, thick full line $=13-15$ species. Scale bar $=3.22 \mathrm{~km}(2 \mathrm{mi})$. 
masses comprise a diverse range of habitats, including maritime shrub communities dominated by Rhus typhina L. (Staghorn Sumac), native and nonnative forests and woodlands, freshwater wetlands, and meadows. Across the BHI, nonnative organisms make up $44 \%$ of the total vascular plant biodiversity (Elliman 2005). The intentional (i.e., ornamental or agricultural) and unintentional introductions of nonnative plants is a key factor determining the distributional patterns of plant associations at the BHI. As a result, even adjacent islands with similar habitats can have strikingly different communities. Proximity to the mainland, history of anthropogenic disturbance, and the size of the landmass in question are all factors that shape the diverse landscapes of the BHI (Elliman 2005) and are expected to also affect the diversity and distribution of fungi.

The sizes and maximum elevations of our field sites, as well as the number of plant species found at each site, are listed in Table 1. Grape Island $\left(42^{\circ} 16^{\prime} 08.44^{\prime \prime} \mathrm{N}\right.$, $\left.70^{\circ} 55^{\prime} 15.05^{\prime \prime} \mathrm{W}\right)$, the smallest of our 4 target sites, consists of 2 drumlins connected by a lowland marsh. The early-successional plant community there is dominated by Staghorn Sumac, Betula populifolia Marshall (Grey Birch), and Populus tremuloides Michx. (Quaking Aspen). During the summer months, Grape Island experiences considerable traffic from campers and hikers (Elliman 2005, National Park Service $2015)$. Peddocks Island $\left(42^{\circ} 17^{\prime} 32.6^{\prime \prime} \mathrm{N}, 70^{\circ} 56^{\prime} 21.6^{\prime \prime} \mathrm{W}\right)$ has a long history of agricultural activity dating back prior to European settlement. The island was an active military station up until the end of World War II, and current forest canopies are dominated by Acer platanoides L. (Norway Maple) (National Park Service 2015). Thompson Island $\left(42^{\circ} 18^{\prime} 54.13^{\prime \prime} \mathrm{N}, 71^{\circ} 00^{\prime} 36.78^{\prime \prime} \mathrm{W}\right)$ supports a mix of hardwood tree stands, ornamental trees and shrubs, open meadows, shrubby areas of successional growth, Staghorn Sumac groves and manicured lawns; it also experiences much human activity (Elliman 2005, National Park Service 2015). World's End $\left(42^{\circ} 16^{\prime} 12^{\prime \prime} \mathrm{N}, 70^{\circ} 52^{\prime} 48^{\prime \prime} \mathrm{W}\right)$ is considered to be the healthiest and most natural of

Table 1. The Boston Harbor Islands National Recreation Area consists of 34 distinct land masses. For our fungal ATBI, we focused collecting efforts on Grape Island, Peddocks Island, Thompson Island, and World's End peninsula, and sparingly sampled 4 more locations. Our target sites represent the largest land masses of the BHI and comprise the greatest plant diversity. For all sampled sites (target and nontarget), the total area (including intertidal zone) and highest altitude are given, along with the number of plant species and the percentage of nonnative plants (Elliman 2005, National Park Service 2015).

\begin{tabular}{lcccc} 
BHI site & Area (ha) & $\begin{array}{c}\text { Highest } \\
\text { elevation (m asl) }\end{array}$ & $\begin{array}{c}\text { Number of } \\
\text { plant species }\end{array}$ & $\begin{array}{c}\text { Nonnative } \\
\text { plant species (\%) }\end{array}$ \\
\hline Grape Island & 21.9 & 21.3 & 172 & 37 \\
Peddocks Island & 74.6 & 24.4 & 225 & 51 \\
Thompson Island & 54.2 & 23.8 & 211 & 50 \\
World's End & 104.5 & 42.7 & 301 & 34 \\
Calf Island & 7.5 & 11.6 & 90 & 59 \\
Great Brewster Island & 7.5 & 32.0 & 108 & 62 \\
Slate Island & 4.8 & 9.8 & 80 & 34 \\
Webb Memorial State Park & 13.9 & N/A & 178 & 51 \\
\hline
\end{tabular}


all the BHI land masses, despite a long history of agricultural use and ornamental landscaping (most notably by landscape architect Frederick Law Olmsted) (National Park Service 2015). It has the largest number of plant species of any of the islands and peninsulas at the BHI, due to its size and diversity of habitats (Elliman 2005). Our remaining field-sites are remote islands of small acreage and low plant diversity dominated by Staghorn Sumac. The exception, Webb Memorial State Park, a peninsular land mass, is smaller than any of the 4 target sites but has similar plant communities (Elliman 2005).

\section{Methods}

\section{Field-collection protocol}

We collected the above-ground, ephemeral fruiting bodies of non-lichenized fungi, those that emerge throughout the year when temperature and humidity are optimal for a given species, and placed the samples in plastic containers or brown paper bags. We assigned specimens a BHI-F collection number and recorded their metadata, including the date, specific locality on the field-site, GPS coordinates (when available), substrate, and surrounding habitat notes. After initial morphological examination, we tentatively assigned names to the specimens. We preserved specimens using a Presto Dehydro food dehydrator (National Presto Industries, Eau Claire, WI) set at $35^{\circ} \mathrm{C}$ for $7-9$ hours. Collections were packaged, labeled, and deposited at the Farlow Herbarium at Harvard University (Cambridge, MA).

\section{Molecular methods}

We removed a rice-sized piece of tissue from each fresh specimen and stored theses samples at $-20{ }^{\circ} \mathrm{C}$ until DNA extraction could be performed. We employed the DNeasy Plant Mini Kit (Qiagen, Valencia, CA), the QIAamp DNA Micro Kit (Qiagen), or the Extract-N-Amp Plant PCR Kit (Sigma-Aldrich, St. Louis, MO) to perform DNA extractions. For the column-based extractions using Qiagen kits, we used a a 1.5-mL pellet pestle (Kimble, Rockwood, TN, \#749521-1500) to macerate fungal tissue in a $1.5-\mathrm{mL}$ tube prior to adding buffer AP1 (DNeasy) or ATL (QIAamp); otherwise, extraction followed the manufacturer's instructions. For Extract-N-Amp extractions, we placed tissue in a $0.5-\mathrm{mL}$ PCR tube, added $20 \mu \mathrm{L}$ of extraction solution, and incubated the tube at room temperature $\left(\sim 24^{\circ} \mathrm{C}\right)$ for 10 $\min -1 \mathrm{~h}$ and then in the thermocycler at $95{ }^{\circ} \mathrm{C}$ for $10 \mathrm{~min}$. After incubation, we added $60 \mu \mathrm{L}$ of dilution solution so that the final ratio of extraction solution to dilution solution was $1: 3$. DNA extractions were stored at $-20^{\circ} \mathrm{C}$ until PCR was done.

PCR amplification targeted the internal transcribed spacer (ITS; composed of ITS1, 5.8S, and ITS2) of the ribosomal RNA gene (rDNA), the region used as the universal DNA barcode for identification of fungi (Schoch et al. 2012). Amplification was carried out using the fungal-specific ITS1F (5'-CTTGGTCATTTAGAGGAAGTAA-3') and ITS4 (5'-TCCTCCGCTTATTGATATGC-3') primer set (Gardes and Bruns 1993). PCR reactions consisted of $13.3 \mu \mathrm{L}$ of Extract-N-Amp PCR ReadyMix (Sigma-Aldrich), $2.5 \mu \mathrm{L}$ of ITS1F forward primer $(10 \mu \mathrm{M}), 2.5$ $\mu \mathrm{L}$ of ITS4 reverse primer $(10 \mu \mathrm{M}), 5.7 \mu \mathrm{L}$ of $\mathrm{H}_{2} \mathrm{O}$, and $1 \mu \mathrm{L}$ of template genomic 
DNA. We set the following thermocycler conditions to amplify ITS rDNA: initial denaturing at $94{ }^{\circ} \mathrm{C}$ for $3: 00 \mathrm{~min}, 35$ cycles of denaturing at $94{ }^{\circ} \mathrm{C}$ for 1:00 min, annealing at $50{ }^{\circ} \mathrm{C}$ for $0: 45 \mathrm{~min}$, extension at $72{ }^{\circ} \mathrm{C}$ for $1: 30 \mathrm{~min}$, and a final extension step of $72^{\circ} \mathrm{C}$ for $10: 00 \mathrm{~min}$.

We visualized PCR products via gel electrophoresis. We purified successfully amplified samples using Qiagen's QIAquick PCR Purification Kit. Nest, we prepared $10-\mu \mathrm{L}$ sequencing reactions with the same primers and $3 \mu \mathrm{L}$ of purified PCR product. We performed sequencing reactions using the BigDye ${ }^{\circledR}$ Terminator v3.1 Cycle Sequencing Kit. Generated sequences were assembled, trimmed, and edited in Sequencher v4.10.1 (Gene Codes Corporation, Ann Arbor, MI). All sequences have been deposited in NCBI GenBank, with accession numbers KF668283, KM463010, KM875555, KX077900, KY765902, MF161161-MF161327, MF289561-MF289562, MG553993-MG553996, MH445964-MH445966, and MH454641.

We employed GenBank's nonredundant sequence database using BLAST to compare and identify sequences; a boundary of $97-99 \%$ sequence similarity with $>80 \%$ query coverage was used to name a species as correctly as possible via the ITS, depending on the fungal group. We evaluated the top matches, and referred any ambiguous or erroneous identifications to experts.

\section{Checklists}

We prepared 2 checklists, an alphabetical list of species and a taxonomic list of species, both with information on the localities where each species was found (Appendices 1,2). Abbreviations of BHI field-sites are as follows: $\mathrm{CI}=$ Calf Island, GBI $=$ Great Brewster Island, GI $=$ Grape Island, PI $=$ Peddocks Island, SI = Slate Island, TI $=$ Thompson Island, WE $=$ World's End, and WMSP $=$ Webb Memorial State Park. Classification followed Index Fungorum (2017). We implemented the most recent taxonomical rearrangements only for the following groups: Leotiomycetes following Baral (2016), and Xylariales following Wendt et al. (2018). Collection data for all specimens included in the checklists are provided in Supplemental File 1 (available online at http://www.eaglehill.us/NENAonline/suppl-files/ n25-sp9-1560g-Haelewaters-s1 and, for BioOne subscribers, at https://dx.doi. org/10.1656/N1560g.s1).

We included the authority and higher classification information (Phylum, Order, Family) for each listing in the taxonomic checklist. Entries with the specific epithet "sp." without any additional characters indicates a collection that was only identified to the level of genus. An entry that contains the specific epithet "sp." with additional characters is either a species that is possibly new to science, if the epithet is numbered without any additional text (e.g., Lactarius sp. 1), or a species whose ITS sequence matches one that has been uploaded to GenBank but has not been matched to a described species (e.g., Lachnum sp. 1 KO-2013). "Incertae sedis" indicates that the taxonomic position of a given species at a given taxonomic level is unknown or disputed.

Numerous individuals were involved in the collection and identification of the specimens included in our checklists: Ann Baeijaert, Alden C. Dirks, Alexander 
Etkind, Bart Buyck, Brian Douglas, members of Boston Mycological Club, ChangLin Zhao, Danny Haelewaters, Donald H. Pfister, Edgar Franck, Esther Verhaeghen, Hans-Otto Baral, Jasmin J. Camacho, Jason Karakehian, James Mitchell, Jacob Plotnick, Joseph Warfel, Kevin Healy, Lara A. Kappler, Lawrence Millman, Luis Quijada, Leif Ryvarden, Michał Gorczak, Nousheen Yousaf, Rosanne Healy, Roo Vandegrift, Sarah Verhaeghen, Teresa Iturriaga, Yu-Ming Ju, and Zaac Chaves.

We performed our analyses of ecological functional groups (or guilds) according to Nguyen et al. (2016). We conducted all analyses in the R language and environment for statistical computing (R Core Team 2013). We constructed a table with species as rows and number of collections and classification for each species as columns as input (see Supplemental File 2, available online at http://www.eaglehill.us/NENAonline/suppl-files/n25-sp9-1560g-Haelewaters-s2 and, for BioOne subscribers, at https://dx.doi.org/10.1656/N1560g.s2). We made our taxonomic assignments using different criteria for different groups of fungi, as outlined above. The Guilds_v1.0.py script (Nguyen et al. 2016) was run in Python to add functional information to the input table, and the resulting output file was used in subsequent analyses in R (see Supplemental File 3, available online at http://www.eaglehill.us/ NENAonline/suppl-files/n25-sp9-1560g-Haelewaters-s3 and, for BioOne subscribers, at https://dx.doi.org/10.1656/N1560g.s3). We employed the following packages for the analyses: 'ape' (Paradis et al. 2004), 'phyloseq' (McMurdie and Holmes 2013), 'ggplot2' (Ginestet 2011), and 'dplyr' (Wickham and Romain 2014).

\section{Results}

\section{Checklists}

Over 900 collections of fungi were sampled by the authors, collaborators, and visiting researchers. Of those, a total of 313 collections have been identified, resulting in 172 species (Fig. 2; see Supplemental File 1, available online at http:// www.eaglehill.us/NENAonline/suppl-files/n25-sp9-1560g-Haelewaters-s 1 and, for BioOne subscribers, at https://dx.doi.org/10.1656/N1560g.s1). The fungal taxa discovered at the BHI are distributed between 2 phyla, 11 classes, 24 orders, 62 families, and 123 genera (Fig. 2). The species are listed alphabetically (Appendix 1) and according to taxonomy (Appendix 2).

\section{Biogeography and ecology}

According to our sampling design and effort, there was generally a positive relationship between area and number of fungal species (Fig. 1, Table 1). The most diverse BHI site was World's End (73 spp.), followed by Grape and Thompson Islands (44 spp. each), and Peddocks Island (35 spp.). We detected 54 species of fungi only at World's End, the highest number of exclusive species of any site. The most widely distributed species were Schizophyllum commune at 6 sites; Artomyces pyxidatus, Daedaleopsis confragosa, Ganoderma applanatum, and Trichaptum biforme at 4 sites each; and Chlorociboria aeruginascens, Crepidotus crocophyllus, Irpex lacteus, Phellinus gilvus, and Trametes versicolor at 3 sites each. World's End had the largest number of samples belonging to the Ectomycorrhizal guild, closely 

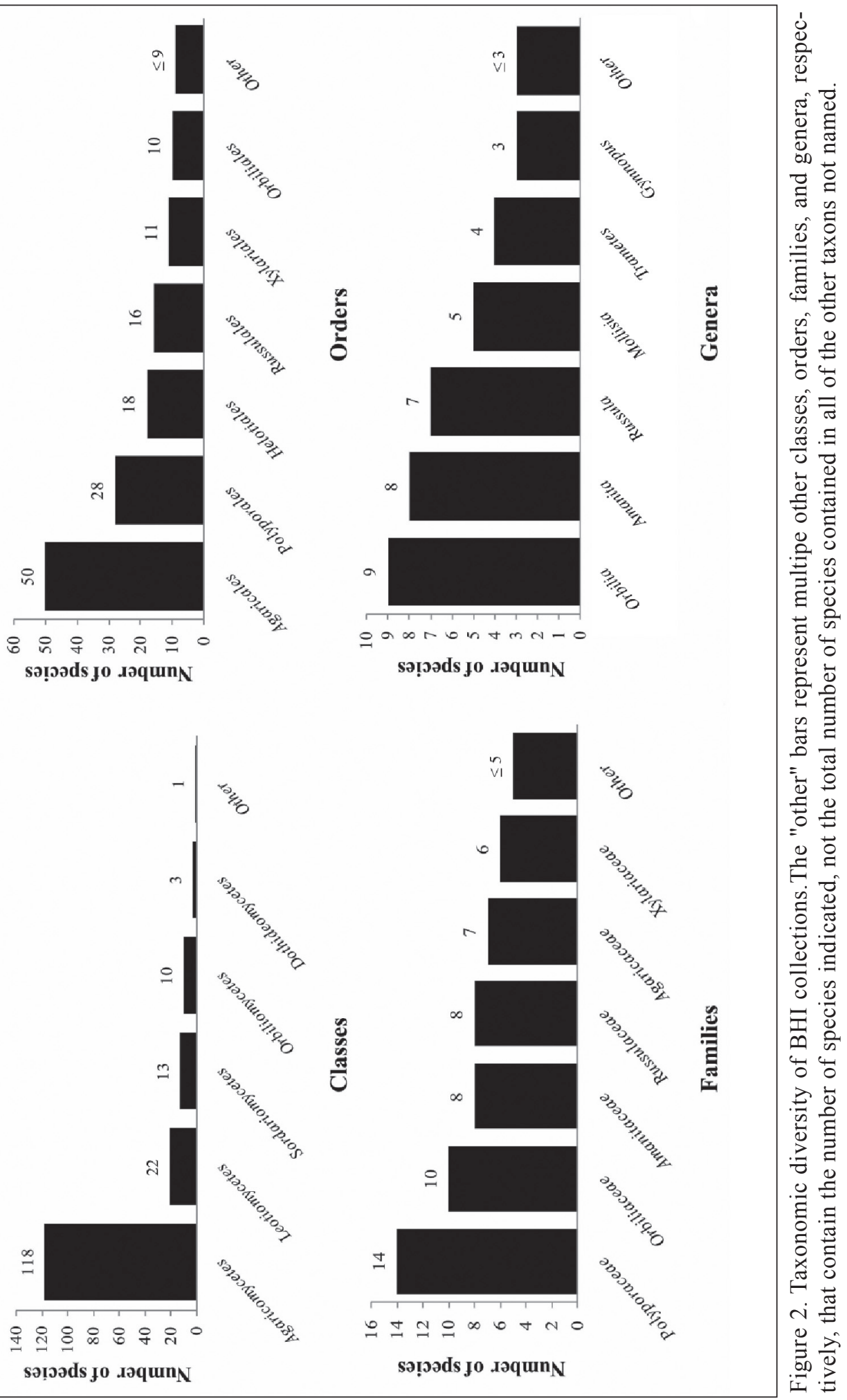
followed by Thompson Island. Peddocks Island had the largest number of samples belonging to Saprotroph guilds (Undefined Saprotroph, Undefined SaprotrophWood Saprotroph, Wood Saprotroph; Fig. 3).

\section{Discussion}

\section{Necessity for preservation of fungi}

The collection and preservation of fruiting bodies found at the Boston Harbor Islands in our fungal ATBI contributes to the extensive specimen inventory of the Farlow Herbarium at Harvard University. Natural science collections, such as these dried fruiting bodies, are physical, lasting evidence of the biodiversity of ecosystems and play an important role in the understanding and documentation of the world biota (NatSCA 2005). The specimens and their associated information (locality, photographs, and description) serve as important data in current and future scientific studies (e.g., taxonomy, systematics, genetics, and conservation biology research), as well as a valued resource for teaching (Funk 2007). For example, historical specimens of lichens from the Farlow Herbarium are being used in the Biology of Fungi undergraduate course at Harvard to showcase biodiversity that no longer exists in Cambridge, MA, because of air pollution and human development. Likewise, the BHI fungal specimens made in this study will serve as a time capsule for researchers of the future to understand the ecological transformations of an important urbanisland national park. Given the enormous advances in molecular technology over the past few decades, it seems likely that techniques yet to be discovered will greatly benefit from well-preserved and annotated historical specimens.

\section{DNA-based identification: advantages and disadvantages}

Although next-generation sequencing technology promises to revolutionize molecular taxonomy, current DNA-based identification focuses on the genes that code for ribosomal RNA (rDNA), in particular the ITS region. Since rDNA is repeated many times in the eukaryote genome, it is especially suitable for PCR amplification and sequencing. Unlike the small (SSU) and large subunits (LSU) of rDNA, which are also commonly used to identify and describe organisms, 2 parts of the ITS (ITS1 and ITS2) are cleaved out of the precursor rRNA and are not incorporated into ribosomes. As a result, these sections generally experience low selection pressure and exhibit much greater genetic variation. The $5.8 \mathrm{~S}$ component, on the other hand, does participate in the function of ribosomes. Consequently, the ITS region consists of 3 scales of interspecific variation (ITS1: rapid evolution; $5.8 \mathrm{~s}$ : highly conserved; and ITS2: moderately rapid evolution), which results in sequence variation that typically reflects species-level classification of fungi (Bazzicalupo et al. 2017, Hershkovitz and Lewis 1996, Hillis and Dixon 1991).

Increasingly, large numbers of ITS sequences are derived from the environment (so-called "environmental sequences" from soil, root samples, etc.) without collecting or preserving an associated voucher specimen. Considering that it could take 4000 years for taxonomists to describe all the species of fungi on Earth using current specimen-based approaches, environmental sequencing may be a welcome 

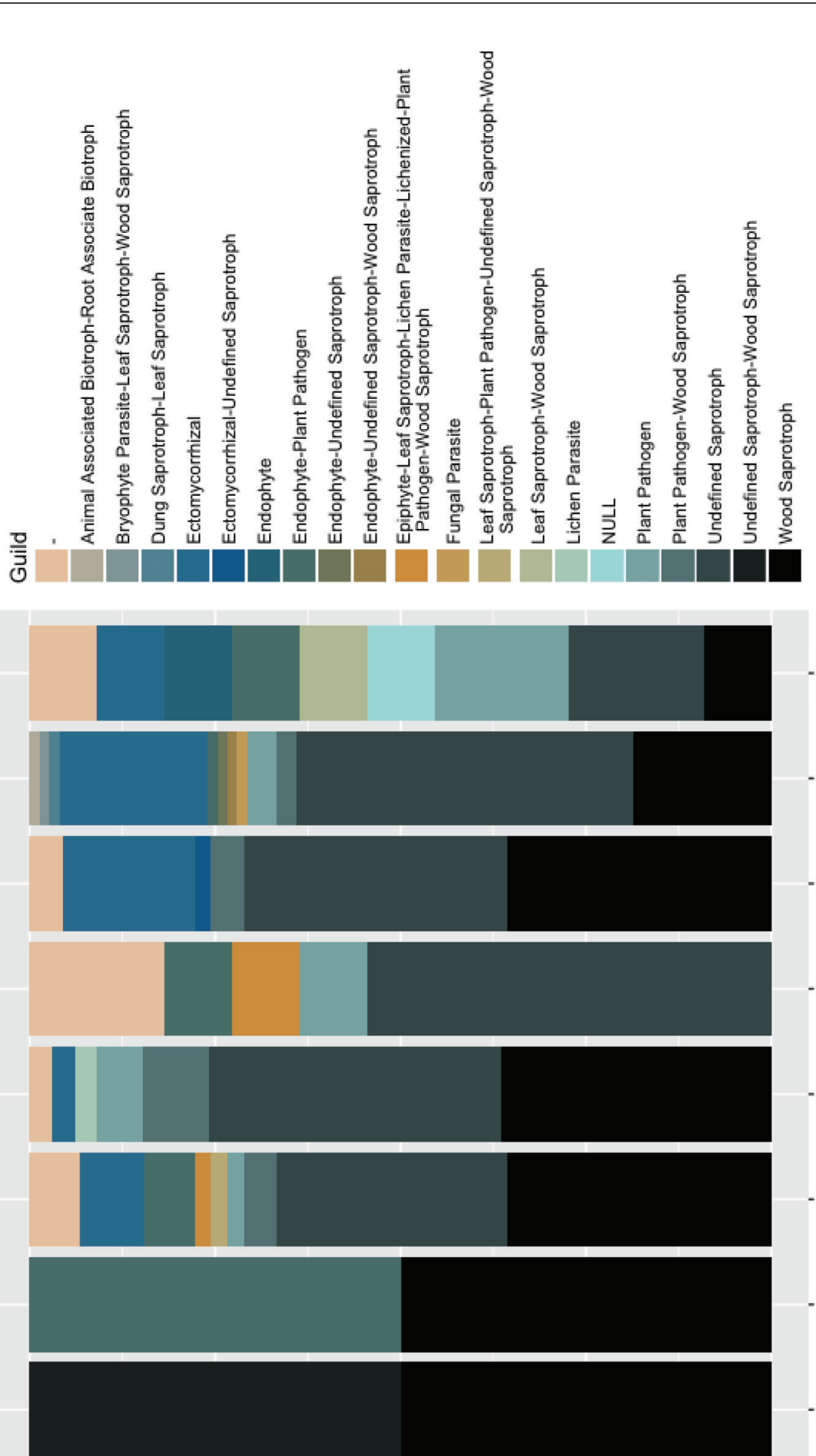

$\dot{8}$

皇

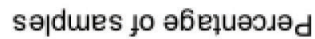


means by which researchers can quickly discover novel fungi and their distribution (Hibbett et al. 2011). Indeed, DNA sequencing of barcode genes-such as the ITS rDNA-for identification and discovery of specimens is relatively fast and inexpensive, and requires far less specialized knowledge than microscopic study of morphological features. However, there are several significant issues associated with switching to predominantly molecular-based discovery and identification methods that warrant discussion.

There are many misidentified fungal sequences in GenBank, the predominant repository of genetic sequences (Kõljalg et al. 2013, Vilgalys 2003). GenBank's misidentifications are caused by many factors, including (1) misidentification of specimens, (2) chimeric sequences, (3) static taxonomic assignments within GenBank, and (4) assignment of taxonomic identity of unknown organisms (e.g. environmental sequences) via the nearest BLAST match, which can propagate errors in the database (Nilsson et al. 2006). In the following paragraphs, we give examples for these factors contributing to the misapplication of fungal names to collections.

Misidentification of specimens. Through both legacy taxonomic assignment and common misidentification, many sequences from western North American collections are mislabeled as Amanita franchetii (Boud.) Fayod. They actually represent the recently described $A$. augusta Bojantchev \& R.M. Davis (Bojantchev and Davis 2012).

Chimeric sequences. Chimeric sequences consist of 2 (bimeras) or more (multimeras) sequence fragments that do not originate from the same species. These compromised sequences can be the result of unintentional joining of fragments during PCR amplification or incorrect assembly of forward and reverse primer reads into a single fragment. Typically, the chimeric breakpoint is located in the 5.8S part, which is the most highly conserved section (Nilsson et al. 2012). Chimeric sequences are usually easy to detect when they consist of fragments from distantly related species, which is most often the situation. Chimeric sequences pose problems in different fields of research, and different tools have been developed for detection (Edgar et al. 2011 and references therein). An assessment of 12 studies using $16 \mathrm{~S}$ rDNA sequences of bacteria yielded 21 inter-phylum and 18 intra-phylum chimeric sequences (Hugenholtz and Huber 2003). Recently, Buyck et al. (2016) discussed the possibility of chimeras in their ITS sequences of species of Elaphomyces (Eurotiales).

Static taxonomic assignments within GenBank. As a prime example, the majority of sequences labeled Daldinia concentrica (Bolton) Ces. \& De Not. are incorrect. Daldinia concentrica has been reported worldwide but is in fact restricted to Europe (sensu stricto, Rogers et al. 1999). The cosmopolitan species generally referred to as $D$. concentrica is in fact $D$. childiae (Stadler et al. 2014). Consequently, the collections of this species encountered during our study are properly named $D$. childiae. In a similar example, the ITS sequence for our Resupinatus Nees ex Gray collection from Grape Island, BHI-F640, BLASTS with 99\% similarity ( $98 \%$ query coverage) with $R$. poriaeformis (Pers.) Thorn, Moncalvo, \& Redhead from Canada, the only sequence available in GenBank for this species. 
However, North American collections of $R$. poriaeformis require a new name, since European and North American collections are separated into 2 distinct clades based on a combined ITS+LSU rDNA dataset (McDonald 2015).

Assignment of taxonomic identity by the highest BLAST match. The top BLAST match for 1 of our mollisioid isolates, BHI-F752a, was Phialocephala fortinii C.J.K. Wang \& H.E. Wilcox (95\% query coverage, 95\% sequence similarity). When comparing our ITS sequence to a larger ITS rDNA dataset of Phialocephala species (sensu Tanney et al. 2016), we found that our sequence (as well as its top BLAST match) clustered together with well-documented sequences for $P$. oblonga.

Considering the above issues, we provide the following recommendations: The results found with a BLAST search require further evaluation, particularly with ITS sequences. Steps include careful consideration of the source and author of sequences, as well as the date they were published or revised. Clustering of the top sequence matches may be useful, as well as consideration of alignable regions (e.g., the $5.8 \mathrm{~S}$ region) independently from ambiguous regions.

\section{Curated databases of fungal barcode sequences}

Both the problem of described species without sequence data and the problem of sequence data without a connection to described species contribute to the lack of understanding of global fungal biodiversity and to the difficulties in creating well-curated databases of fungal barcode sequences, such as the UNITE database (Kõljalg et al. 2005, 2013). In the UNITE database, reference sequences (RefS) are determined by experts for each species hypothesis ( $\mathrm{SH}$ ) at different sequencesimilarity cut-offs that are appropriate for any given species (Kõljalg et al. 2013). All public fungal ITS sequences are clustered by UNITE to the genus/subgenus level, and thereafter clustered again to produce operational taxonomic units corresponding to the species level. These "taxa" that arise from the second round of clustering are referred to as hypotheses.

A comprehensive reference database of sequences is necessary for trustworthy identification. Only a small number of the currently described species of fungi has been sequenced at the ITS locus, many fewer other informative loci are available, and searchable sequence databases are far from complete. For example, between 1999 and 2009 , only $26 \%$ of newly described species had sequences deposited in GenBank (Hibbett et al. 2011), and although that number has increased (to $60 \%$ in 2015), it is still far less than complete coverage (Hibbett et al. 2016). For some groups, such as the Laboulbeniales, it is a notable exception to publish sequences alongside new species-ITS sequences are deposited in GenBank for only 18 of the 2100 described species in the order (29 August 2017).

\section{Interesting collections from the BHI National Recreation Area}

Through a combination of sequencing and morphological analysis of fungal specimens collected from the Boston Harbor Islands, we made important contributions to fungal taxonomy and demonstrated that there are novel species to be discovered even in a highly trafficked location serving large urban areas. We found 4 species of fungi new to science: in the genera Orbilia Fr. (collected in September 
2013 and March 2017), Resupinatus (March 2017), and Xylaria Hill ex Schrank (winter 2016/2017). Another collection, in the genus Lactarius Pers. (July 2015), may be a new species, though further study is necessary, including comparison with types and multi-locus sequencing for phylogenetic placement (A. Verbeken, Ghent University, Ghent, Belgium, pers. comm.). We have deposited ITS rDNA sequences into GenBank for the first time for 6 species found at the BHI (Table 2).

We discovered many other important species, including Orbilia aprilis, a small apothecial fungus (discomycete) newly reported in North America, as well as Durella aff. melanochlora, Mollisia ligni, and Proliferodiscus earoleucus-3 discomycetes rarely reported for North America. Although Durella melanochlora has been collected in Canada on a few occasions (in British Columbia), it has not yet been reported from the US (MyCoPortal 2018). Previous to our work, Proliferodiscus earoleucus had only been reported in the US once (as Trichopeziza earoleuca in South Carolina; MyCoPortal 2018). Remarkably, 3 of these species were collected from a single piece of wood at a weedy, trash-strewn site on Slate Island, collected in March 2017 (Table 2, Fig. 1). This finding demonstrates that small, less charismatic fungi are severely undersampled. Indeed, many inconspicuous or enigmatic fungi are only known from the type collection or a few collections in restricted areas, primarily locations close to the homes or institutes of researchers who study them. Notorious examples are fungi in the orders Helotiales, Laboulbeniales, and Xylariales. Furthermore, these discoveries reflect the need not only to explore urban biodiversity, but also to conduct fieldwork during all seasons. Fungi are undersampled during winter in temperate ecosystems due to the presumption that fruiting bodies are absent. Although large fruiting bodies may not be found, smaller ascomycetes are abundant and can be easier to locate when ground cover and foliage have died back.

Table 2. Notable finds from our fungal biodiversity inventory of the Boston Harbor Islands. New $=$ new species to be described after morphological study and multi-locus sequencing, Rep $=$ new report for North America, Seq = first published ITS rDNA sequence(s) deposited in GenBank, and Sub = newly reported substrate. See text for abbreviations.

\begin{tabular}{|c|c|c|c|c|c|c|}
\hline BHI-F \# & Site & Species & New & Rep & Seq & Sub \\
\hline BHI-F387 & GI & Lactarius sp. 1 & $\mathrm{X}$ & & & \\
\hline BHI-F502, BHI-F743 & WE & Xylaria sp. 1 & $\mathrm{X}$ & & & \\
\hline BHI-F612 & CI & Chrysosporium sulfureum & & & & $\mathrm{X}$ \\
\hline BHI-F624 & SI & Proliferodiscus earoleucus & & & $\mathrm{X}$ & \\
\hline BHI-F626 & SI & Mollisia ligni & & & $\mathrm{X}$ & \\
\hline BHI-F628 & SI & Orbilia aprilis & & $\mathrm{X}$ & & \\
\hline BHI-F632 & SI & Dendrothele nivosa & & & $\mathrm{X}$ & \\
\hline BHI-F640 & GI & Resupinatus sp. 1 & $\mathrm{X}$ & & & \\
\hline BHI-F652 & GI & Durella aff. melanochlora & & & $\mathrm{X}$ & \\
\hline BHI-F730 & WE & Dasyscyphella nivea & & & $\mathrm{X}$ & \\
\hline BHI-F731 & WE & Orbilia sp. 1 & $\mathrm{X}$ & & & \\
\hline BHI-F097, BHI-F108 & WE & Orbilia sp. 2 & $\mathrm{X}$ & & & \\
\hline BHI-F736, BHI-F737 & WE & Chlorosplenium chlora & & & $\mathrm{X}$ & \\
\hline
\end{tabular}


Another notable discovery, the anamorphic fungus Chrysosporium sulfureum, was found to be growing as an entomopathogenic fungus on woodlice (Crustacea, Malacostraca, Isopoda, Oniscidea). This species, colloquially called fleur jaune ("yellow flower"), is a common fungus in some cheeses, spreading across the rind as white growth and sporulating into a yellow mass (Wolfe 2015). It is known to grow well in cave environments at $14-18{ }^{\circ} \mathrm{C}$ (Wolfe 2015), although in our study it was growing prolifically in early March at a temperature of $\sim 9{ }^{\circ} \mathrm{C}$. Other species in this non-monophyletic genus are keratinolytic and some even cause severe infections in humans (Vidal et al. 2000). Vidal et al. (2000) showed that $C$. sulfureum belongs to a clade of apparently non-keratinolytic species; further studies are required, however, to understand the life history of C. sulphureum and its potentially keratinolytic/chitinolytic and cryophilic physiology.

Our checklist is a much-needed contribution to public repositories of DNA sequences and the overall documentation of fungal diversity. Other biodiversity inventories, like those conducted by Truong et al. (2017) in southern South America, demonstrate the exceptional progress that focused collection efforts can make towards our understanding of fungal diversity. They generated over 300 novel clusters of ITS sequences with $97-99 \%$ similarity, representing $1.5 \%$ of the total diversity in the UNITE database. One quarter of their vouchered specimens had ITS sequences that matched pre-existing environmental sequences without vouchered specimens, creating a more robust and complete understanding of organisms that had been detected only via sequences. Certainly, undersampled regions continue to be rich sources of new biodiversity information; our study, however, indicates that even "oversampled" regions with a long history of mycological investigation are replete with undiscovered diversity and require increased sampling efforts. Given the inexpensive and accessible sequencing technology available today, there are more opportunities than ever to involve large numbers of students in the discovery and documentation of hidden fungal diversity, all the while exciting the next generation of conservationists and biologists.

\section{Conclusions}

We conducted a fungal inventory at Boston Harbor Islands National Recreation Area, located off the coast of Boston, MA. Of the more than 900 collections, 313 have been identified, yielding 172 species in 123 genera. Six of our collections represent 4 new species in the genera Orbilia, Resupinatus, and Xylaria. A collection of Lactarius may be new to science but needs further study (morphological and molecular phylogenetic). Our finding of Orbilia aprilis represent a first report for North America, and we found Proliferodiscus earoleucus for only the second time in the US. In addition to listing taxonomic findings, we also discussed sequencebased identification of fungal collections and factors contributing to misidentified entries in open databases such as GenBank. A comprehensive, curated database with reference sequences selected by taxonomic experts is necessary for trustworthy identification of samples. A recent effort is the UNITE database, which currently holds over 73,000 species hypotheses. Finally, we highlighted 2 species for which European names have traditionally but incorrectly been applied to North 
American collections: Daldinia childiae and Resupinatus sp. 1. There is need for a meta-analysis to analyze North American and European literature for genera in which such collections can be designated. Critical taxonomic studies that combine both morphological and molecular phylogenetic data are necessary to adopt the correct names of collections in different geographic areas of the planet. A common problem with these collections is that there are described species without sequence data and sequence data without taxonomic assignment.

\section{Acknowledgments}

A.C. Dirks and L.A. Kappler contributed equally to this paper. D. Haelewaters was funded for his fungal inventory work by Boston Harbor Now, the National Park Service and by the New England Botanical Club through its Les Mehrhoff Botanical Research Fund. L.A. Kappler and A.C. Dirks were funded by Boston Harbor Now and the National Park Service. Marc Albert provided logistic support and invaluable input to the manuscript and the entire project. Russ Bowles and his staff at the Division of Marine Operations at the University of Massachusetts Boston provided expert navigation and transportation to the remote islands of the BHI. Rosanne Healy provided advice and assisted during the initial stages of this project. Else Vellinga was kind enough to help with the discussion about ITS. This study would be nothing without many colleagues, visiting researchers, friends, and family who aided in the collection and identification of fungi: Ann Baeijaert, Jasmin Camacho, Zachary Chavez, Alex Etkind, Edgar Franck, Kevin Healy, Rosanne Healy, Teresa Iturriaga, Lawrence Millman, Jacob Plotnick, Leif Ryvarden, Greg Thorn, Esther Verhaeghen, Sarah Verhaeghen, Joseph Warfel, Nousheen Yousaf, and Chang-Lin Zhao.

\section{Literature Cited}

Baral, H.-O. 2016. Inoperculate discomycetes. Pp 157-205, In W. Jaklitsch, H.-O. Baral, R. Lücking, H.T. Lumbsch, and W. Frey (Eds.). Syllabus of Plant Families: A. Engler's Syllabus der Pflanzenfamilien Part 1/2. Borntraeger, Stuttgart, Germany. 322 pp.

Bass, D., and T.A. Richards. 2011. Three reasons to re-evaluate fungal diversity "on Earth and in the ocean". Fungal Biology Reviews 25:159-164.

Bazzicalupo, A.L., B. Buyck, I. Saar, J. Vauras, D. Carmean, and M.L. Berbee. 2017. Troubles with mycorrhizal mushroom identification where morphological differentiation lags behind barcode-sequence divergence. Taxon 66:791-810.

Begerow, D., H. Nilsson, M. Unterseher, and W. Maier. 2010. Current state and perspectives of fungal DNA barcoding and rapid identification procedures. Applied Microbiology and Biotechnology 87:99-108.

Blackwell, M. 2011. The Fungi: 1, 2, 3 ... 5.1 million species? American Journal of Botany 98:426-438.

Blaxter, M.L. 2004. The promise of a DNA taxonomy. Philosophical Transactions of the Royal Society B 359:669-679.

Bluhm, B.A., A.V. Gebruk, R. Gradinger, R.R. Hopcroft, F. Huettmann, K.N. Kosobokova, B.I. Sirenko, and J.M. Weslawski. 2011. Arctic marine biodiversity: An update of species richness and examples of biodiversity change. Oceanography 24:232-248.

Bojantchev, D., and R.M. Davis. 2012. Amanita augusta, a new species from California and the Pacific Northwest. North American Fungi 8:1-11.

Brazee, N.J., D.L Lindner, S. Fraver, A.W. D’Amato, A.M. Milo. 2012. Wood-inhabiting, polyporoid fungi in aspen-dominated forests managed for biomass in the US Lake States. Fungal Ecology 5:600-609. 
Buyck, B., K. Hosaka, S. Masi, and V. Hofstetter. 2016. Molecular analyses of first collections of Elaphomyces Nees (Elaphomycetaceae, Eurotiales, Ascomycota) from Africa and Madagascar indicate that the current concept of Elaphomyces is polyphyletic. Cryptogamie, Mycologie 37:3-14.

Edgar, R.C., B.J. Haas, J.C. Clemente, C. Quince, and R. Knight. 2011. UCHIME improves sensitivity and speed of chimera detection. Bioinformatics 27:2194-2200.

Elliman, T. 2005. Vascular flora and plant communities of the Boston Harbor Islands. Northeastern Naturalist Special Issue 3:49-75.

Fancy, S.G., J.E. Gross, and S.L. Carter. 2009. Monitoring the condition of natural resources in US National Parks. Environmental Monitoring and Assessment 151:161-174.

Funk V. 2007. 100 Uses for a Herbarium (well at least 72). Virtual herbarium, Fairchild Tropical Botanic Garden. Available online at http://botany.si.edu/documents/2003 Funk_100Uses.pdf. Accessed 19 June 2017.

Gardes, M., and T.D. Bruns. 1993. ITS Primers with enhanced specificity for Basidiomycetes: Application to the identification of mycorrhizae and rusts. Molecular Ecology 2:113-118.

Ginestet, C. 2011. ggplot2: Elegant graphics for data analysis. Journal of the Royal Statistical Society: Series A 174:245-246.

Haelewaters, D., S.Y. Zhao, A.D. Kesel, R.E. Handlin, I.R. Royer, B.D. Farrell, and D.H. Pfister. 2015. Laboulbeniales (Ascomycota) of the Boston Harbor Islands I: Species parasitizing Coccinellidae and Staphylinidae, with comments on typification. Northeastern Naturalist 22:459-477.

Hawksworth, D.L., and R. Lücking. 2017. Fungal diversity revisited: 2.2 to 3.8 million species. Microbiology Spectrum 5(4). DOI:10.1128/microbiolspec.FUNK-0052-2016

Hershkovitz, M.A., and L.A. Lewis. 1996. Deep-level diagnostic value of the rDNA-ITS region. Molecular Biology and Evolution 13:1276-1295.

Hibbett, D.S., Ohman A., Glotzer D., Nuhn M., Kirk P., and R.H. Nilsson. 2011. Progress in molecular and morphological taxon discovery in Fungi and options for formal classification of environmental sequences. Fungal Biology Reviews 25:38-47.

Hibbett, D., K. Abarenkov, U. Koljalg, M. Opik, B. Chai, J.R. Cole, Q. Wang, P.W. Crous, V.A. Robert, T. Helgason, J. Herr, P. Kirk, S. Lueschow, K. O’Donnell, H. Nilsson, R. Oono, C.L. Schoch, C. Smyth, D. Walker, A. Porras-Alfaro, J.W. Taylor, and D.M. Geiser. 2016. Sequence-based classification and identification of Fungi. Mycologia 108:1049-1068.

Hillis, D.M., and M.T. Dixon. 1991. Ribosomal DNA: Molecular evolution and phylogenetic inference. The Quarterly Review of Biology 66:411-453.

Himmelstoss, E.A, D.M. FitzGerald, P.S. Rosen, and J.R. Allen. 2006. Bluff evolution along coastal drumlins: Boston Harbor Islands, Massachusetts. Journal of Coastal Research 22:1230-1240.

Hugenholtz, P., and T. Huber. 2003. Chimeric 16S rDNA sequences of diverse origin are accumulating in the public databases. International Journal of Systematic and Evolutionary Microbiology 53:289-293.

Index Fungorum. 2017. Search Index Fungorum. Available online at http://http://www. indexfungorum.org/Names/Names.asp. Accessed 7 August 2017.

Janzen, D.H., and W. Hallwachs. 1994. All Taxa Biodiversity Inventory (ATBI) of terrestrial systems: A generic protocol for preparing wildland biodiversity for non-damaging use. Report of an NSF Workshop, 16-18 April 1993. Philadelphia, PA. 132 pp. 
D. Haelewaters, et al.

Kõljalg, U., K.-H. Larsson, K. Abarenkov, R.H. Nilsson, I.J. Alexander, U. Eberhardt, S. Erland, K. Høiland, R. Kjøller, E. Larsson, T. Pennanen, R. Sen, A.F.S. Taylor, L. Tedersoo, T. Vrålstad, and B.M. Ursing. 2005. UNITE: A database providing web-based methods for the molecular identification of ectomycorrhizal fungi. New Phytologist 166:1063-1068.

Kõljalg, U., R.H. Nilsson, K. Abarenkov, L. Tedersoo, A.F.S. Taylor, M. Bahram, S.T. Bates, T.D. Bruns, J. Bengtsson-Palme, T.M. Callaghan, B. Douglas, T. Drenkhan, U. Eberhardt, M. Dueñas, T. Grebenc, G.W. Griffith, M. Hartmann, P.M. Kirk, P. Kohout, E. Larsson, B.D. Lindahl, R. Lücking, M.P. Martín, P.B. Matheny, N.H. Nguyen, T. Niskanen, J. Oja, K.G. Peay, U. Peintner, M. Peterson, K. Põldmaa, L. Saag, I. Saar, A. Schüßler, J.A. Scott, C. Senés, M.E. Smith, A. Suija, D.L. Taylor, M.T. Telleria, M. Weiß, and K.H. Larsson. 2013. Towards a unified paradigm for sequence-based identification of fungi. Molecular Ecology 22:5271-5277.

Korf, R.P. 2005. Reinventing taxonomy: A curmudgeon's view of 250 years of fungal taxonomy, the crisis in biodiversity, and the pitfalls of the phylogenetic age. Mycotaxon 93:407-415.

LaGreca, S., E. Lay, D. Greene, E. Kneiper, and M. Lincoln, M. 2005. The lichens and bryophytes of the Boston Harbor Islands. Northeastern Naturalist 12:77-98.

Lazarus, A. 2013. Observer cards: Ants. Available online at http://eol.org/info/disc observer\#ants. Accessed 15 June 2017.

McDonald, J. 2015. Morphological and molecular systematics of Resupinatus (Basidiomycota). Ph.D. Dissertation. The University of Western Ontario, London, ON, Canada. $299 \mathrm{pp}$.

McMurdie, P.J., and S. Holmes. 2013. phyloseq: An R package for reproducible interactive analysis and graphics of microbiome census data. PLoS ONE 8:e61217.

MyCoPortal. 2018. Available online at http://mycoportal.org/portal/collections/index.php. Accessed 13 March 2018.

National Park Service. 2015. Island Facts. Boston Harbor Islands National Recreation Area. US Department of the Interior, 26 February. Available online at https://www.nps.gov/ boha/learn/historyculture/facts-intro.htm. Accessed 29 June 2017.

Natural Science Collections Association (NatSCA). 2005. A matter of life and death. Natural science collections: Why keep them and why fund them? Available online at http:// natsca.info/sites/natsca.info/files/AMatterOfLifeAndDeath.pdf. Accessed 13 June 2017.

Nguyen, N.H., Z. Song, S.T. Bates, S. Branco, L. Tedersoo, J. Menke, J.S. Schilling, and P.G. Kennedy. 2016. FUNGuild: An open annotation tool for parsing fungal community datasets by ecological guild. Fungal Ecology 20:241-248.

Nilsson, R.H., M. Ryberg, E. Kristiansson, K. Abarenkov, K.H. Larsson, and U. Kõljalg. 2006. Taxonomic reliability of DNA sequences in public sequence-databases: A fungal perspective. PLoS ONE 1:e59.

Nilsson, R.H., G. Bok, M. Ryberg, E. Kristiansson, and N. Hallenberg. 2009. A software pipeline for processing and identification of fungal ITS sequences. Source Code for Biology and Medicine 4:1.

Nilsson, R.H., L. Tedersoo, K. Abarenkov, M. Ryberg, E. Kristiansson, M. Hartmann, C.L. Schoch, J.A. Nylander, J. Bergsten, T.M. Porter, A. Jumpponen, P. Vaishampayan, O. Ovaskainen, N. Hallenberg, J. Bengtsson-Palme, K.M. Eriksson, K.-H. Larsson, E. Larsson, and U. Kõljalg. 2012. Five simple guidelines for establishing basic authenticity and reliability of newly generated fungal ITS sequences. MycoKeys 4:37-63.

Paradis, E., J. Claude, and K. Strimmer. 2004. APE: Analyses of phylogenetics and evolution in R language. Bioinformatics 20:289-290. 
Pimm, S.L., C.N. Jenkins, R. Abell, T.M. Brooks, J.L. Gittleman, L.N. Joppa, P.H. Raven, C.M. Roberts, and J.O. Sexton. 2014. The biodiversity of species and their rates of extinction, distribution, and protection. Science 344:1246752.

R Core Team. 2013. R: A language and environment for statistical computing. R Foundation for Statistical Computing, Vienna, Austria. Available online at http://www.R-project. org. Accessed 28 September 2017.

Rogers, J.D., Y.M. Ju, R. Watling, and A.J.S. Whalley. 1999. A reinterpretation of Daldinia concentrica based upon a recently discovered specimen. Mycotaxon 72:507-520.

Rykken, J. 2013. Observer cards: Bees. Available online at http://eol.org/info/disc observer\#bees. Accessed 15 June 2017.

Rykken, J.J., and B.D. Farrell. 2013. Boston Harbor Islands All Taxa Biodiversity Inventory: Discovering the "microwilderness" of an urban island park. Natural Resource Technical Report NPS/BOHA/NRTR—2013/746. National Park Service, Fort Collins, CO. Available online at https://irma.nps.gov/App/Reference/Profile/2195282. Accessed 12 January 2017.

Schoch, C.L., K.A. Seifert, S. Huhndorf, V. Robert, J.L. Spouge, C.A. Levesque, W. Chen, E. Bolchacova, K. Voigt, P.W. Crous, and A.N. Miller. 2012. Nuclear ribosomal internal transcribed spacer (ITS) region as a universal DNA barcode marker for Fungi. Proceedings of the National Academy of Sciences 109:6241-6246.

Snow, E.R. 1984. The Islands of Boston Harbor, 1630-1971. Dodd, Mead, and Company, New York, NY. 274 pp.

Stadler, M., T. Læssøe, J. Fournier, C. Decock, B. Schmieschek, H.V. Tichy, and D. Peršoh. 2014. A polyphasic taxonomy of Daldinia (Xylariaceae). Studies in Mycology 77:1-143.

Tanney, J.B., B. Douglas, and K.A. Seifert. 2016. Sexual and asexual states of some endophytic Phialocephala species of Picea. Mycologia 108:255-280.

Trowbridge, C.D., Y.M. Hirano, and J. Yoshiaki. 2011. Inventory of Japanese sacoglossan opisthobranchs: Historical review, current records, and unresolved issues. American Malacological Bulletin 29:1-22.

Truong, C., A.B. Mujic, R. Healy, F. Kuhar, G. Furci, D. Torres, T. Niskanen, P.A. Sandoval-Leiva, N. Fernández, J.M. Escobar, A. Moretto, G. Palfner, D. Pfister, E. Nouhra, R. Swenie, M. Sánchez-García, P.B. Matheny, and M.E. Smith. 2017. How to know the fungi: Combining field inventories and DNA-barcoding to document fungal diversity. New Phytologist 214:913-919.

Vidal, P., M. de los Angeles Vinuesa, J.M. Sánchez-Puelles, and J. Guarro. 2000. Phylogeny of the anamorphic genus Chrysosporium and related taxa based on rDNA internal transcribed spacer sequences. Revista Iberoamericana de Micología 17:22-29.

Vilgalys, R. 2003. Taxonomic misidentification in public DNA databases. New Phytologist 160:4-5.

Wendt, L., E.B. Sir, E. Kuhnert, S. Heitkämper, C. Lambert, A.I. Hladki, A.I. Romero, J.J. Luangsa-ard, P. Srikitikulchai, D. Peršoh, and M. Stadler. 2018. Resurrection and emendation of the Hypoxylaceae, recognised from a multigene phylogeny of the Xylariales. Mycological Progress 17:115-154. DOI:10.1007/s11557-017-1311-3

Wickham, H., and F. Romain. 2014. dplyr: A grammar of data manipulation. R package version 0.2 . Available online at http://cran.r-project.org/web/packages/dplyr. Accessed 28 September 2017.

Wolfe, B. 2015. Microbe guide: Chrysosporium sulfureum. Available online at http://microbialfoods.org/microbe-guide-chrysosporium-sulfureum/. Accessed 7 August 2017.

Zimkus, B. 2015. Observer cards: Frogs. Available online at http://eol.org/info/disc observer\#frogs. Accessed 15 June 2017. 


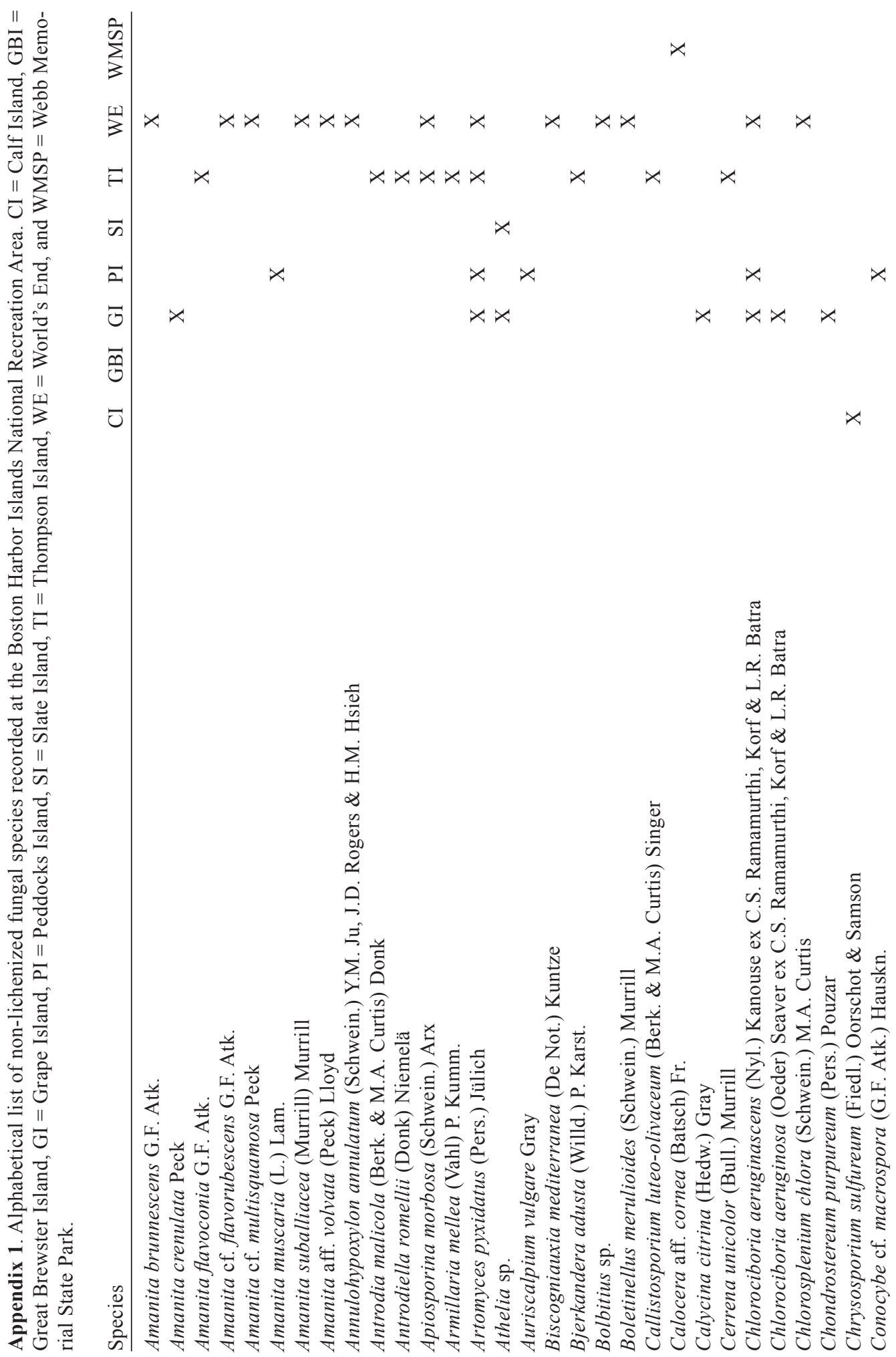




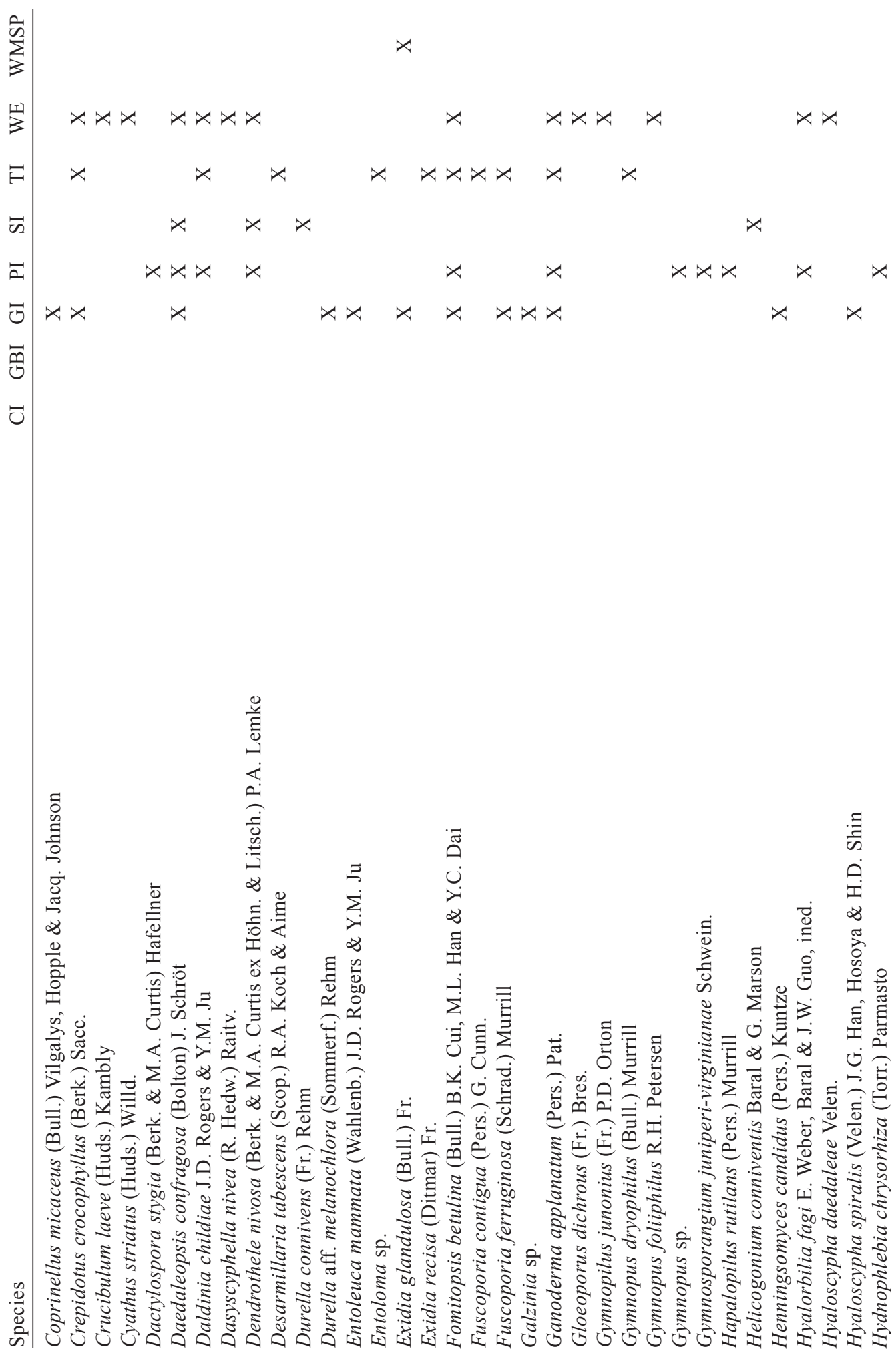



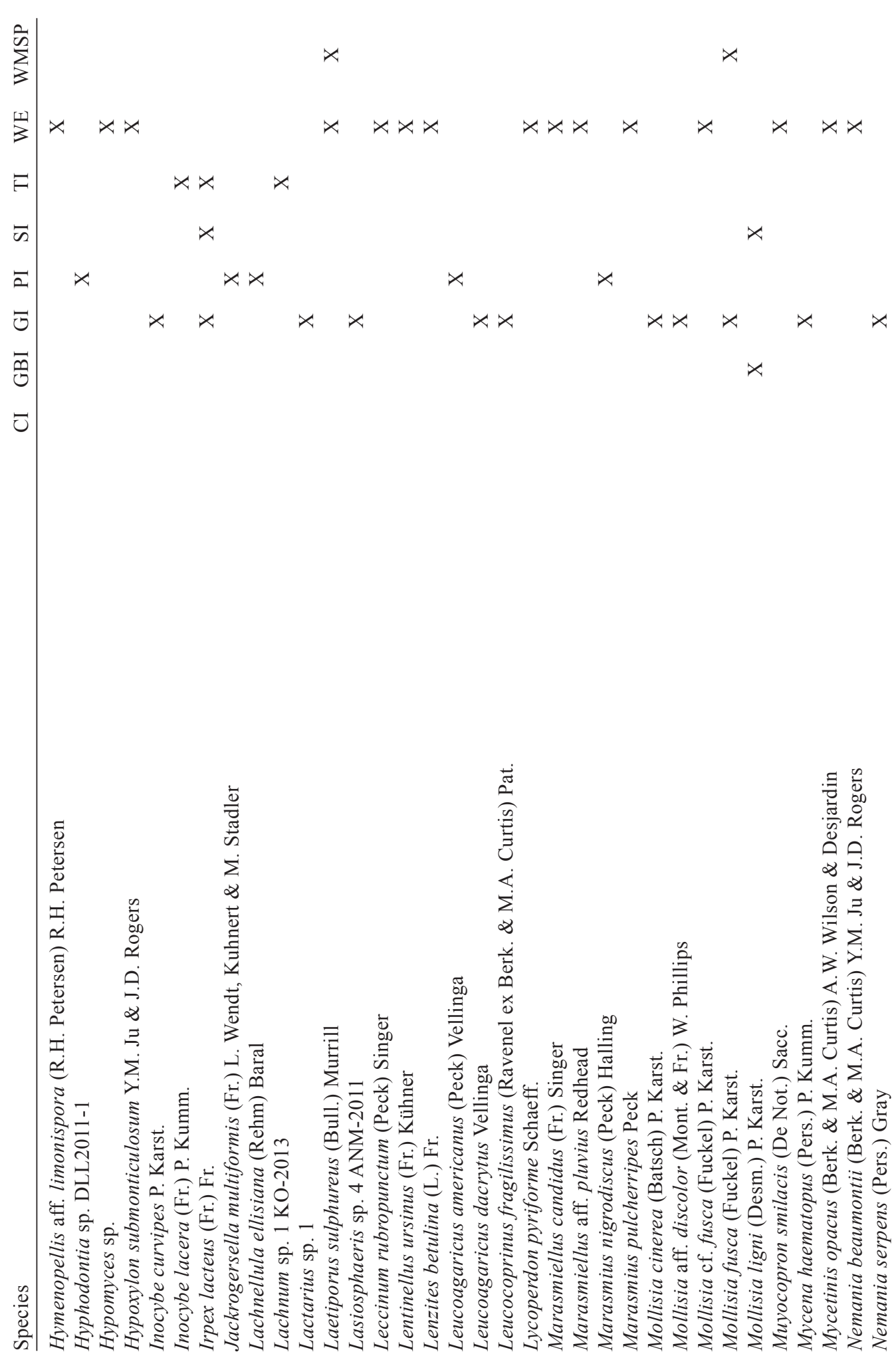


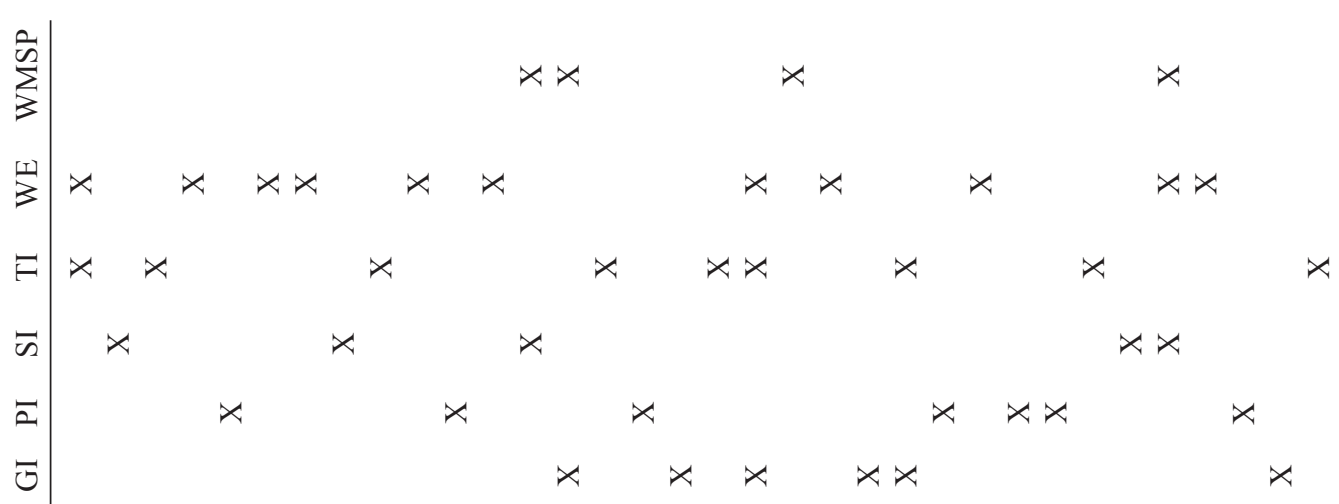

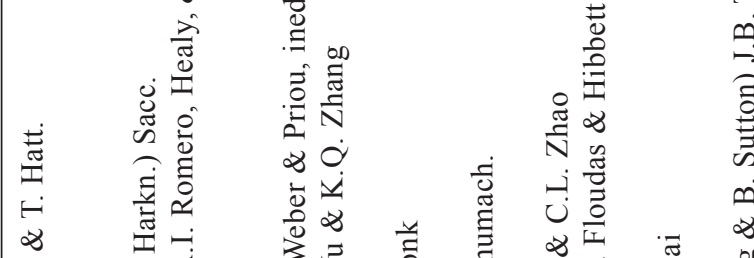

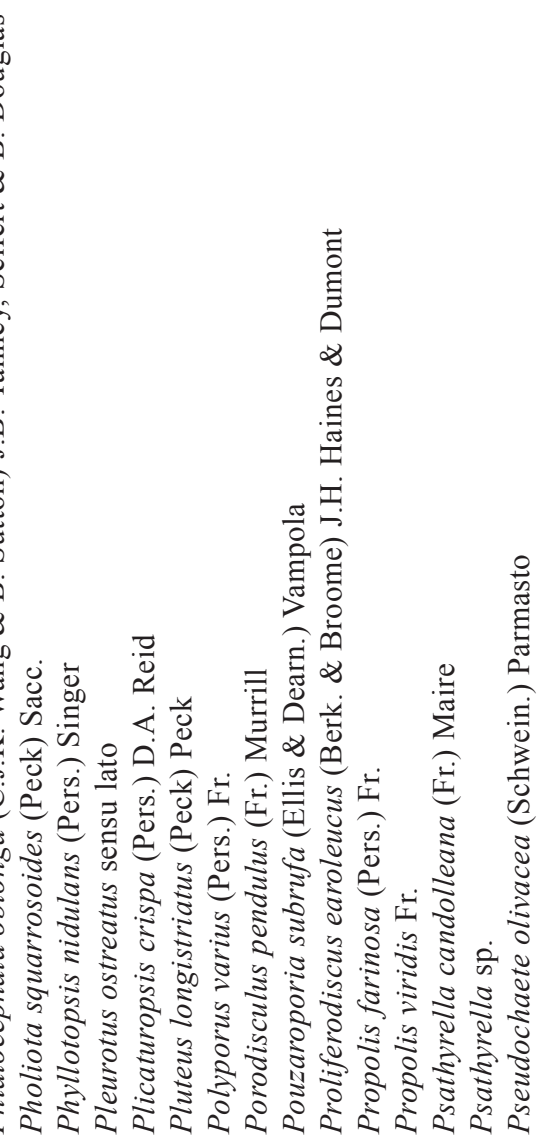




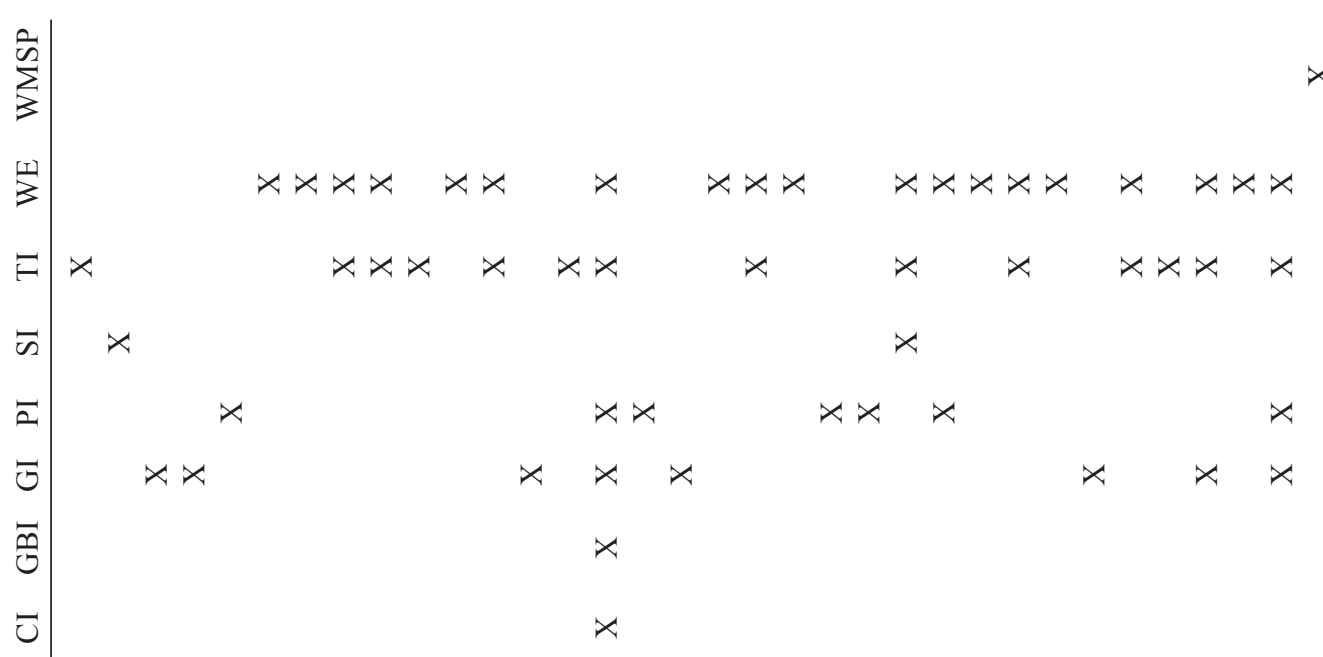




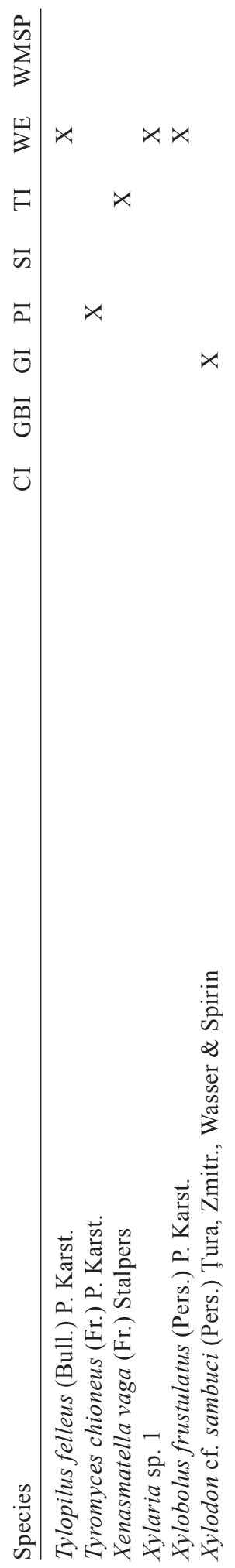


Appendix 2. Taxonomic list of non-lichenized fungal species recorded at the Boston Harbor Islands National Recreation Area. Given are PHYLUM, subphylum, and then indented class, subclass, order, and family. $\mathrm{CI}=$ Calf Island, $\mathrm{GBI}=$ Great Brewster Island, $\mathrm{GI}=$ Grape Island, PI $=$ Peddocks Island, $\mathrm{SI}=$ Slate Island, $\mathrm{TI}=$ Thompson Island, $\mathrm{WE}=$ World's End, and WMSP $=$ Webb Memorial State Park.

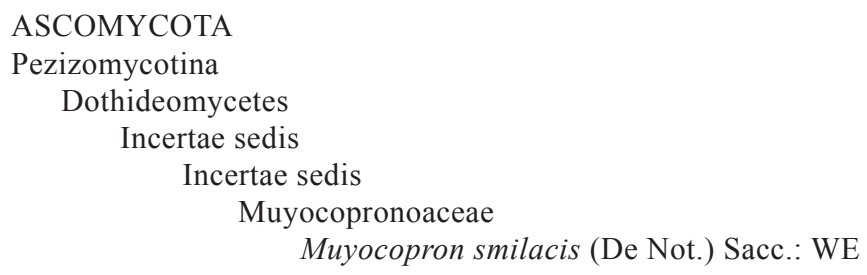

Eurotiomycetes

Eurotiomycetidae

Onygenales

Onygenaceae

Chrysosporium sulfureum (Fiedl.) Oorschot \& Samson: CI

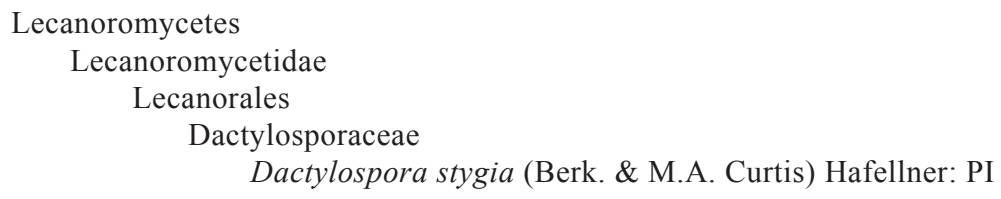

Chlorociboria aeruginosa (Oeder) Seaver ex C.S. Ramamurthi, Korf \& L.R.

Batra: GI

Hyaloscyphaceae

Hyaloscypha daedaleae Velen.: WE

Hyaloscypha spiralis (Velen.) J.G. Han, Hosoya \& H.D. Shin: GI

Incertae sedis

Chlorosplenium chlora (Schwein.) M.A. Curtis: WE

Lachnaceae

Dasyscyphella nivea (R. Hedw.) Raitv.: WE

Lachnellula ellisiana (Rehm) Baral: PI

Lachnum sp. 1 KO-2013: TI

Proliferodiscus earoleucus (Berk. \& Broome) J.H. Haines \& Dumont: SI 
Mollisiaceae

Mollisia cinerea (Batsch) P. Karst.: GI

Mollisia aff. discolor (Mont. \& Fr.) W. Phillips: GI

Mollisia cf. fusca (Fuckel) P. Karst.: WE

Mollisia fusca (Fuckel) P. Karst.: GI, WMSP

Mollisia ligni (Desm.) P. Karst.: GBI, SI

Phialocephala oblonga (C.J.K. Wang \& B. Sutton) J.B. Tanney, Seifert \& B. Douglas: WMSP

Mollisiaceae sensu lato

Durella connivens (Fr.) Rehm: SI

Durella aff. melanochlora (Sommerf.) Rehm: GI

Pezizellaceae

Calycina citrina (Hedw.) Gray: GI

Phacidiales

Helicogoniaceae

Helicogonium conniventis Baral \& G. Marson: SI

Rhytismatales

Marthamycetaceae

Propolis farinosa (Pers.) Fr.: SI, WE, WMSP

Propolis viridis $\mathrm{Fr}$.: WE

Rhytismataceae

Rhytisma acerinum (Pers.) Fr.: PI

Orbiliomycetes

Orbiliomycetidae

Orbiliales

Orbiliaceae

Hyalorbilia fagi E. Weber, Baral \& J.W. Guo, ined.: PI, WE

Orbilia aprilis Velen.: SI

Orbilia cf. cejpii Velen.: TI

Orbilia aff. eucalypti (W. Phillips \& Harkn.) Sacc.: WE

Orbilia nemaspora Baral, Bin Liu, A.I. Romero \& Pfister, ined.: PI

Orbilia sp. 1: WE

Orbilia sp. 2: WE

Orbilia cf. subclaviformis Baral, E. Weber \& Priou, ined.: SI

Orbilia cf. vermiformis Baral, Z.F. Yu \& K.Q. Zhang: TI

Orbilia aff. xanthostigma (Fr.) Fr.: WE

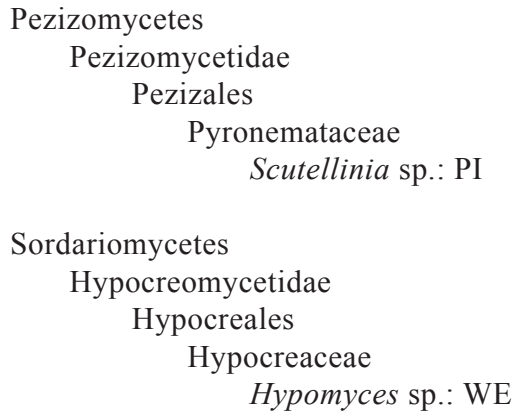



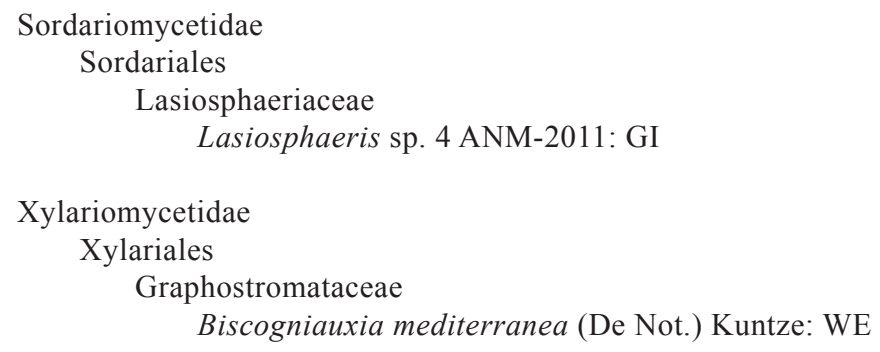

Hypoxylaceae

Annulohypoxylon annulatum (Schwein.) Y.M. Ju, J.D. Rogers \& H.M. Hsieh: WE

Daldinia childiae J.D. Rogers \& Y.M. Ju: PI, TI, WE

Hypoxylon submonticulosum Y.M. Ju \& J.D. Rogers: WE

Jackrogersella multiformis (Fr.) L. Wendt, Kuhnert \& M. Stadler: PI

Xylariaceae

Entoleuca mammata (Wahlenb.) J.D. Rogers \& Y.M. Ju: GI

Nemania beaumontii (Berk. \& M.A. Curtis) Y.M. Ju \& J.D. Rogers: WE

Nemania serpens (Pers.) Gray: GI

Rosellinia corticium (Schwein.) Sacc.: WE

Rosellinia subiculata (Schwein.) Sacc.: WE

Xylaria sp. 1: WE

\section{BASIDIOMYCOTA}

Agaricomycotina

Agaricomycetes

Agaricomycetidae

Agaricales

Agaricaceae

Crucibulum laeve (Huds.) Kambly: WE

Cyathus striatus (Huds.) Willd.: WE

Leucoagaricus americanus (Peck) Vellinga: PI

Leucoagaricus dacrytus Vellinga: GI

Leucocoprinus fragilissimus (Ravenel ex Berk. \& M.A. Curtis) Pat.: GI

Lycoperdon pyriforme Schaeff.: WE

Amanitaceae

Amanita brunnescens G.F. Atk.: WE

Amanita crenulata Peck: GI

Amanita flavoconia G.F. Atk.: TI

Amanita cf. flavorubescens G.F. Atk.: WE

Amanita cf. multisquamosa Peck: WE

Amanita muscaria (L.) Lam.: PI

Amanita suballiacea (Murrill) Murrill: WE

Amanita aff. volvata (Peck) Lloyd: WE

Bolbitiaceae

Bolbitius sp.: WE

Conocybe cf. macrospora (G.F. Atk.) Hauskn.: PI

Cyphellaceae

Chondrostereum purpureum (Pers.) Pouzar: GI 
Entolomataceae

Entoloma sp.: TI

Hymenogastraceae

Gymnopilus junonius (Fr.) P.D. Orton: WE

Incertae sedis

Plicaturopsis crispa (Pers.) D.A. Reid: PI

Inocybaceae

Crepidotus crocophyllus (Berk.) Sacc.: GI, TI, WE

Inocybe curvipes P. Karst.: GI

Inocybe lacera (Fr.) P. Kumm.: TI

Marasmiacaea

Henningsomyces candidus (Pers.) Kuntze: GI

Tetrapyrgos nigripes (Fr.) E. Horak: WE

Marasmius nigrodiscus (Peck) Halling: PI

Marasmius pulcherripes Peck: WE

Mycenaceae

Mycena haematopus (Pers.) P. Kumm.: GI

Panellus stipticus (Bull.) P. Karst.: WE

Omphalotaceae

Gymnopus sp.: PI

Gymnopus dryophilus (Bull.) Murrill: TI

Gymnopus foliiphilus R.H. Petersen: WE

Marasmiellus candidus (Fr.) Singer: WE

Marasmiellus aff. pluvius Redhead: WE

Mycetinis opacus (Berk. \& M.A. Curtis) A.W. Wilson \& Desjardin: WE

Physalacriaceae

Armillaria mellea (Vahl) P. Kumm.: TI

Desarmillaria tabescens (Scop.) R.A. Koch \& Aime: TI

Hymenopellis aff. limonispora (R.H. Petersen) R.H. Petersen: WE

Pleurotaceae

Pleurotus ostreatus sensu lato: GI, TI

Pluteaceae

Pluteus longistriatus (Peck) Peck: WE

Psathyrellaceae

Coprinellus micaceus (Bull.) Vilgalys, Hopple \& Jacq. Johnson: GI

Psathyrella sp.: GI

Psathyrella candolleana (Fr.) Maire: PI

Schizophyllaceae

Schizophyllum commune Fr.: CI, GBI, GI, PI, TI, WE

Strophariaceae

Pholiota squarrosoides (Peck) Sacc.: WE 
Tricholomataceae

Callistosporium luteo-olivaceum (Berk. \& M.A. Curtis) Singer: TI

Phyllotopsis nidulans (Pers.) Singer: GI

Resupinatus sp. 1: GI

Tubariaceae

Tubaria furfuracea sensu lato: WMSP

Atheliales

Atheliaceae

Athelia sp.: GI, SI

Fistulinaceae

Porodisculus pendulus (Fr.) Murrill: PI

Boletales

Boletaceae

Leccinum rubropunctum (Peck) Singer: WE

Strobilomyces strobilaceus (Scop.) Berk.: TI, WE

Tylopilus felleus (Bull.) P. Karst.: WE

Boletinellaceae

Boletinellus merulioides (Schwein.) Murrill: WE

Sclerodermataceae

Scleroderma areolatum Ehrenb.: WE

Scleroderma bovista Fr.: TI, WE

Scleroderma citrinum Pers.: WE

Incertae sedis

Auriculariales

Auriculariaceae

Exidia glandulosa (Bull.) Fr.: GI, WMSP

Exidia recisa (Ditmar) Fr.: TI

Corticiales

Corticiaceae

Dendrothele nivosa (Berk. \& M.A. Curtis ex Höhn. \& Litsch.) P.A. Lemke: PI, SI, WE

Galzinia sp.: GI

Punctularia strigosozonata (Schwein.) P.H.B. Talbot: SI

Hymenochaetales

Hymenochaetaceae

Fuscoporia contigua (Pers.) G. Cunn.: TI

Fuscoporia ferruginosa (Schrad.) Murrill: GI, TI

Phellinopsis conchata (Pers.) Y.C. Dai: TI

Phellinus gilvus (Schwein.) Pat.: GI, TI, WE

Pseudochaete olivacea (Schwein.) Parmasto: TI

Schizoporaceae

Hyphodontia sp. DLL2011-1: PI

Schizopora sp. 1 sensu Brazee et al. (2012): PI 
D. Haelewaters, et al.

Schizopora sp. 2 sensu Brazee et al. (2012): GI

Xylodon cf. sambuci (Pers.) Țura, Zmitr., Wasser \& Spirin: GI

Incertae sedis

Incertae sedis

Oxyporus populinus (Schumach.) Donk: PI

Polyporales

Fomitopsidaceae

Antrodia malicola (Berk. \& M.A. Curtis) Donk: TI

Fomitopsis betulina (Bull.) B.K. Cui, M.L. Han \& Y.C. Dai: GI, PI, TI, WE

Laetiporus sulphureus (Bull.) Murrill: TI, WE

Ganodermataceae

Ganoderma applanatum (Pers.) Pat.: GI, PI, TI, WE

Meruliaceae

Bjerkandera adusta (Willd.) P. Karst.: TI

Gloeoporus dichrous (Fr.) Bres.: WE

Hydnophlebia chrysorhiza (Torr.) Parmasto: PI

Irpex lacteus (Fr.) Fr.: GI, PI, TI

Steccherinum ochraceum (Pers.) Gray: PI

Phanerochaetaceae

Antrodiella romellii (Donk) Niemelä: TI

Phanerochaete sanguineocarnosa D. Floudas \& Hibbett: PI

Phanerochaete sp.: GI

Pouzaroporia subrufa (Ellis \& Dearn.) Vampola: TI

Polyporaceae

Cerrena unicolor (Bull.) Murrill: TI

Daedaleopsis confragosa (Bolton) J. Schröt: GI, PI, TI, WE

Hapalopilus rutilans (Pers.) Murrill: PI

Lenzites betulina (L.) Fr.: WE

Neofavolus alveolaris (DC.) Sotome \& T. Hatt.: TI, WE

Perenniporia nanlingensis B.K. Cui \& C.L. Zhao: TI

Polyporus varius (Pers.) Fr.: PI

Pycnoporus cinnabarinus (Jacq.) P. Karst.: GI

Trametes gibbosa (Pers.) Fr.: GI

Trametes hirsuta (Wulfen) Lloyd: TI, WE

Trametes ochracea (Pers.) Gilb. \& Ryvarden: TI

Trametes versicolor (L.) Lloyd: GI, TI, WE

Trichaptum biforme (Fr.) Ryvarden: GI, PI, TI, WE

Tyromyces chioneus (Fr.) P. Karst.: PI

Xenasmataceae

Xenasmatella vaga (Fr.) Stalpers: TI

Russulales

Auriscalpiaceae

Artomyces pyxidatus (Pers.) Jülich: GI, PI, TI, WE

Auriscalpium vulgare Gray: PI

Lentinellus ursinus (Fr.) Kühner: WE

Peniophoraceae

Peniophora rufa (Fr.) Boidin: GI, WMSP 
Russulaceae

Lactarius sp. 1: GI

Russula mariae Peck: TI, WE

Russula modesta Peck sensu Fatto: TI, WE

Russula mutabilis Murrill: TI

Russula pectinatoides Peck: WE

Russula aff. subsulphurea Murrill: TI, WE

Russula ventricosipes Peck: GI

Russula vesicatoria Murrill: TI

Stereaceae

Stereum complicatum (Fr.) Fr.: TI, SI, WE

Stereum ostrea (Blume \& T. Nees) Fr.: PI, WE

Stereum sanguinolentum (Alb. \& Schwein.) Fr.: WE

Xylobolus frustulatus (Pers.) P. Karst.: WE

Phallomycetidae

Phallales

Phallaceae

Pseudocolus fusiformis (E. Fisch.) Lloyd: TI

Dacrymycetes

Incertae sedis

Dacrymycetales

Dacrymycetaceae

Calocera aff. cornea (Batsch) Fr.: WMSP

Tremellomycetes

Incertae sedis

Tremellales

Tremellaceae

Tremella foliacea Pers.: WE

\author{
Pucciniomycotina \\ Pucciniomycetes \\ Incertae sedis \\ Pucciniales \\ Pucciniaceae \\ Gymnosporangium juniperi-virginianae Schwein.: PI
}

